
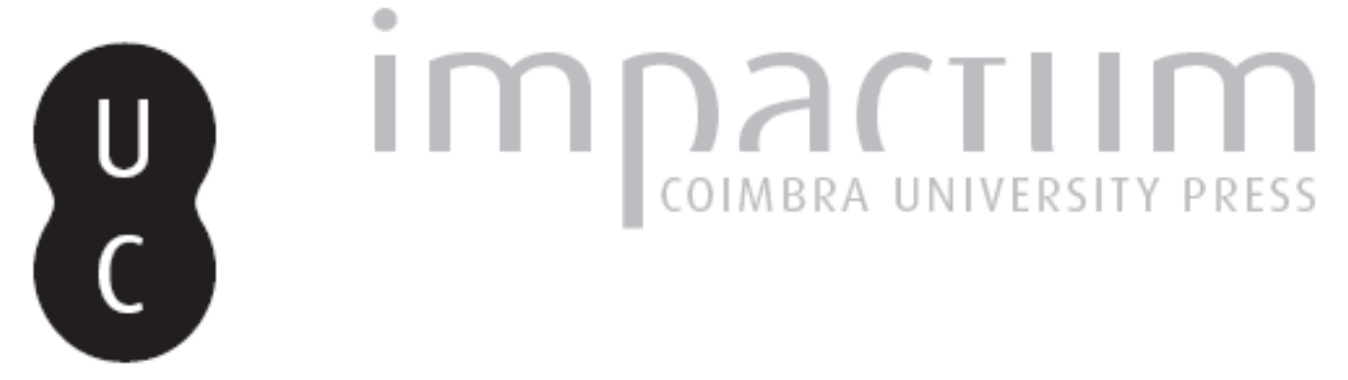

\title{
[Recensão a] Grethlein, J. (2013). Experience and Teleology in Ancient Historiography. 'Futures Past' from Herodotus to Augustine
}

\author{
Autor(es): $\quad$ Sierra, César \\ Publicado por: Annablume Clássica; Imprensa da Universidade de Coimbra \\ URL \\ persistente: \\ URl:http://hdl.handle.net/10316.2/39286 \\ DOI: \\ DOI:http://dx.doi.org/10.14195/1984-249X_18_13 \\ Accessed : $\quad$ 26-Apr-2023 11:37:08
}

A navegação consulta e descarregamento dos títulos inseridos nas Bibliotecas Digitais UC Digitalis, UC Pombalina e UC Impactum, pressupõem a aceitação plena e sem reservas dos Termos e Condições de Uso destas Bibliotecas Digitais, disponíveis em https://digitalis.uc.pt/pt-pt/termos.

Conforme exposto nos referidos Termos e Condições de Uso, o descarregamento de títulos de acesso restrito requer uma licença válida de autorização devendo o utilizador aceder ao(s) documento(s) a partir de um endereço de IP da instituição detentora da supramencionada licença.

Ao utilizador é apenas permitido o descarregamento para uso pessoal, pelo que o emprego do(s) título(s) descarregado(s) para outro fim, designadamente comercial, carece de autorização do respetivo autor ou editor da obra.

Na medida em que todas as obras da UC Digitalis se encontram protegidas pelo Código do Direito de Autor e Direitos Conexos e demais legislação aplicável, toda a cópia, parcial ou total, deste documento, nos casos em que é legalmente admitida, deverá conter ou fazer-se acompanhar por este aviso.

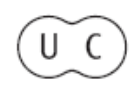




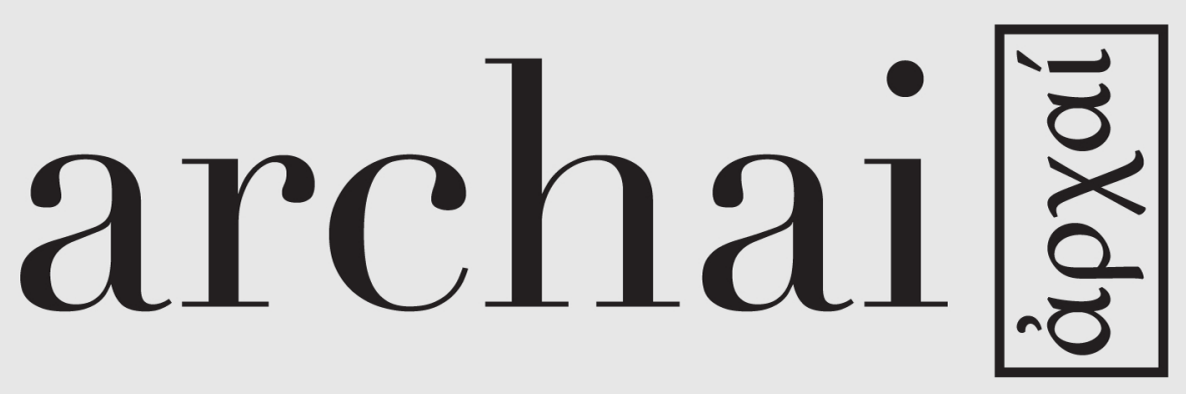

Revista sobre as origens do pensamento ocidental Journal on the Origins of Western Thought

18 | sep.-dec. 2016 
Grethlein, J. (2013).

\section{EXPERIENCE AND TELEOLOGY}

IN ANCIENT HistoriograpHy.

\section{'Futures PAST' FROM}

\section{Herodotus to Augustine.}

Cambridge, Cambridge

University Press

SIERRA, C. (2016). Reseña: Grethlein, J. (2013). Experience and Teleology in Ancient Historiography. 'Futures Past' from Herodotus to Augustine. Cambridge, Cambridge University Press. Archai, no 18, sept.-dec., p. 407-416.

DOI: http://dx.doi.org/10.14195/1984-249X_18_13

Lo primero que me ha venido a la mente tras leer la propuesta de Jonas Grethlein es que se trata de un libro que trabaja las técnicas de los historiadores para generar sensaciones en los lectores. Concretamente

archai圈

n 18 , sept.-dec. 2016 


\section{archai圈}

no 18 , sept.-dec. 2016

César Sierra, Reseña: 'Grethlein, J. (2013). Experience and Teleo$\log y$ in Ancient Historiography. 'Futures Past' from Herodotus to Augustine, Cambridge, Cambridge University Press', p. 407-416 aborda cómo la historiografía desarrolló una narrativa empática, destacando los siguientes rasgos: teleología, enárgeia (viveza en la narración) y mímesis. Por descontado que el análisis es mucho más rico y elaborado pero destaco las que, a mi juicio, son los recursos más analizados en el libro. El autor parte de una larga investigación sobre este tema lo cual se nota en la calidad del resultado.

La estructura del libro se divide en una introducción metodológica y tres apartados centrales: I) Experience: making the past present; II) Teleology: the power of retrospect; y III) Beyond experience and teleology. En la primera parte se aborda el estudio de Tucídides, Jenofonte, Plutarco y Tácito; en la segunda tenemos a Heródoto, Polibio y Salustio; y, finamente, se analizan las Confesiones de Agustín de Hipona. Una trayectoria que abarca prácticamente toda la Antigüedad clásica y orienta la obra hacia una perspectiva global de la historiografía. Todo ello viene acompañado de una edición esmerada, que cuenta con los siempre útiles índices onomásticos y de pasajes citados además de una recopilación bibliográfica final. Magnífica edición como es habitual en las publicaciones de Cambridge University Press.

No muchos historiadores están en condiciones de abarcar con solvencia un período tan amplio como propone Grethlein y ello es muy loable, como también lo es su atención a las diferentes sensibilidades y escuelas historiográficas modernas. La selecta bibliografía en varios idiomas da buena cuenta de mi aserto. Por mi parte, centraré la discusión en aquellos autores que más he trabajado: Heródoto, Tucídides, Jenofonte, Polibio y Plutarco. 
Respecto a Heródoto, el autor destaca el uso de la retrospección en su conocidas digresiones (p.185). Desde mi punto de vista, el autor selecciona muy bien los pasajes en los que Heródoto introduce al público en el relato. Por ejemplo, las lágrimas de Jerjes en el Helesponto cuando contempla su ejército en todo su esplendor cruzando el paso y se lamenta de que toda esa muchedumbre desaparecerá con el tiempo, reflexión sobre lo efímero de la grandeza y la vida humana (Hdt.7.56.2). Al respecto Grethlein capta muy bien que esta alusión a lo que ve y dice el monarca persa es una técnica narrativa para poner al público en una situación en la que el pasado se hace presente. También es muy destacable su análisis del lenguaje críptico de los oráculos, que precisan de una elevada hermenéutica para ser descifrados. En concreto, el autor centra su atención en los signos (sêmeîon) que introducen los oráculos en la narración de Heródoto, un presagio a menudo interpretado erróneamente por los humanos. Valgan como ejemplos el oráculo que vaticinó la ruina de Creso (Hdt.1.54.1), interpretado erróneamente por el monarca lidio, y el famoso oráculo sobre la muralla de madera que debía proteger a los atenienses frente a Jerjes, bien descifrado por Temístocles (Hdt. 8.51.1). Creo que el autor acierta al señalar que la obra de Heródoto con frecuencia traslada al lector adelante en el tiempo y prueba de ello es que la Historia termina con la toma de Sesto por la Liga de Delos, los infortunios amorosos de Jerjes con su hermana y las enigmáticas palabras de Ciro I sobre la degeneración moral de los persas. Todo ello introduce la idea de que un imperio decae mientras otro nace (p. 206-207).

En cambio, la descripción moral o psicológica de los protagonistas persas no está suficientemente bien

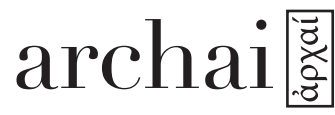

$n^{\text {o }} 18$, sept.-dec. 2016

César Sierra, Reseña: 'Grethlein, J. (2013). Experience and Teleo$\log y$ in Ancient Historiography. 'Futures Past' from Herodotus to Augustine, Cambridge, Cambridge University Press', p. 407-416 


\section{archai圈}

no 18 , sept.-dec. 2016

César Sierra, Reseña: 'Grethlein, J. (2013). Experience and Teleology in Ancient Historiography. 'Futures Past' from Herodotus to Augustine, Cambridge, Cambridge University Press', p. 407-416

\section{0}

trabajada. Bajo mi punto de vista, las cualidades y defectos de personajes como Jerjes o Leónidas responden a modelos que tienen sus raíces en la épica griega. Por ejemplo, Jerjes representa un monarca arrogante y despótico, comparable en algunos rasgos al Agamenón homérico; que contrasta con el sacrificio de Leónidas cuyo trágico destino es similar al de Aquiles ${ }^{1}$. Por tanto, Heródoto simplifica los rasgos de la personalidad de los protagonistas persas con la voluntad de acercarlos al público griego. Todo ello influye también en su relato historiográfico.

El análisis de Grethlein sobre Tucídides se centra en el 'presentismo' y la elaborada técnica del ateniense a la hora de introducir pequeños detalles en la narración. Me ha gustado especialmente el análisis del célebre discurso fúnebre de Pericles (p. 50), presentado como un argumento fuertemente teleológico. También la costumbre del ateniense al avanzar los planes estratégicos y después narrar los eventos, de esta manera el lector puede aventurar el resultado. El autor está muy acertado destacando que se introducen pequeños detalles en la descripción de batallas o se define el estado de ánimo de los ejércitos con la intención de generar empatía en el lector. Son datos intrascendentes para la comprensión del fenómeno objeto de estudio pero que sirven para captar la atención del lector y generar un escenario. Por ejemplo, en el debate sobre la suerte de los mitilenos (Th.3.36) el autor llama la atención sobre el suspense creado por Tucídides (p.44). Como sabemos, se decidía en Asamblea la suerte de los sublevados de Mitilene y, en una primera votación, los atenienses decidieron ejecutarlos a todos, enviando una nave con dicha orden; no obstante, tras deliberar mejor la situación decidieron no suprimirlos a todos 
y enviaron otra nave que tuvo que adelantarse a la anterior para transmitir las órdenes correctas. Esto se puede explicar de muchas maneras pero, como indica Grethlein, es notable la intención de Tucídides de generar un suspense trágico.

Acerca del análisis que se realiza en el libro sobre la obra de Tucídides, sólo reseñar que sería recomendable incluir una valoración sobre la 'Pentecontecia'. En mi opinión, hay una división básica a nivel metodológico entre el libro I y el resto de la obra de Tucídides. El primer libro cumple la función de prefacio donde se aborda el pasado griego anterior a la guerra del Peloponeso desde una óptica fuertemente teleológica, por ejemplo: los episodios de Pausanias y Temístocles, la 'Arqueología', la citada 'Pentecontecia'. La cuestión está muy estudiada y pienso que ayudaría a completar el buen enfoque que el autor ha realizado sobre Tucídides ${ }^{2}$.

Personalmente considero que el mejor capítulo del libro es el dedicado al estudio de la Anábasis de Jenofonte. En esta ocasión el foco de la narración pasa del exterior al interior de la acción. El autor percibe muy bien el giro narrativo que toma la Anábasis tras la muerte de los generales griegos $(A n .3 .1 .4)$ y el cambio total de contexto tras Cunaxa. Ciertamente a partir de la emboscada que termina con el mando de la tropa mercenaria, la narración se aproxima gradualmente hacia Jenofonte, quien adquiere protagonismo en la improvisada dirección de los Diez Mil. Se destaca el valor narrativo de los diálogos y discursos a sabiendas de que el lector interpreta que son de primera mano. Lo anterior genera una sensación casi novelesca de la narración que tiene su punto álgido en la llegada de los

\section{archai圈}

$\mathrm{n}^{\mathrm{o}} 18$, sept.-dec. 2016

César Sierra, Reseña: 'Grethlein, J. (2013). Experience and Teleo$\log y$ in Ancient Historiography. 'Futures Past' from Herodotus to Augustine, Cambridge, Cambridge University Press', p. 407-416 


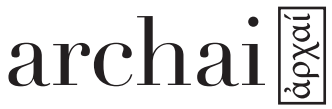

no 18 , sept.-dec. 2016
César Sierra, Reseña: 'Grethlein, J. (2013). Experience and Teleology in Ancient Historiography. 'Futures Past' from Herodotus to Augustine, Cambridge, Cambridge University Press', p. 407-416 griegos al mar (p.60). Para mantener el 'presentismo' y la tensión narrativa, Jenofonte utiliza un gran abanico de recursos: descripción, focalización interna, discursos, presagios y finales abiertos. Estos rasgos otorgan a la Anábasis un carácter 'empírico’ muy particular.

Lo único objetable a este apartado es que el autor no haya realizado alguna anotación al hecho de que Tucídides también fue protagonista de la acción histórica. Como sabemos, el historiador era estratego cuando Anfípolis cayó en manos del espartano Brasidas (Th.5.10). Su participación y responsabilidad en este conflicto condicionaron su interpretación del suceso, valorando positivamente a Brasidas y negativamente a Cleón ${ }^{3}$. Hubiera sido interesante valorar los recursos expositivos de Tucídides en relación a este suceso y al conjunto de la obra.

La buena dinámica que el autor sostiene a lo largo del libro se mantiene en su análisis de Polibio. En este caso abunda en la enárgeia, con especial atención al ambiente que se vivió durante la proclamación de la libertad griega patrocinada por Flaminino en los Juegos Ístmicos (Plb.18.46.12), o la vívida descripción del paso de Escipión entre los cadáveres del campo de batalla en Zama (Plb.38.20.1). Sin embargo, lo que más me ha llamado la atención son las interesantes aportaciones sobre teoría de la historia que se plantean tras valorar el uso del término historíe en Polibio (1.3.4). No cabe duda de que este análisis rompe con la monotonía del libro y enriquece su aportación. No obstante, merecería la pena realizar un análisis más completo para apreciar la evolución del término desde el siglo $\mathrm{V}$ a.C. hasta ese preciso pasaje donde se utiliza en su acepción moderna. De esta forma apreciaríamos me- 
jor le peculiaridad que propone Polibio ${ }^{4}$ (p.230). Por lo demás, el capítulo nos parece de lo más edificante.

Finalmente, llegamos al apartado que más desentona con el buen nivel del libro. Para un libro de esta temática considero que no es acertada la inclusión de Plutarco y su Vida de Alejandro. El autor es consciente del problema que supone añadir una biografía, máxime cuando el propio Plutarco sostiene que no escribía historia (Plu. Alex.1.1). Personalmente no me convence la justificación de Grethlein en las primeras páginas del capítulo. No digo que sea imposible el análisis, sólo pienso que los objetivos, la finalidad y el público potencial de la biografía y la historiografía no coinciden. Aparte podemos considerar la diferencia metodológica entre ambos géneros. No obstante, comprendo la posición del autor al señalar que Plutarco no era refractario a la historiografía, de hecho, para elaborar sus biografías utiliza en gran medida fuentes históricas. En este sentido, Historia y biografía mantienen un delicado equilibrio pero considero el vínculo insuficiente. Por ejemplo, en Sobre la malevolencia de Heródoto, el biógrafo sostiene que un historiador debe decantarse por la narración de los actos buenos y nobles (Plu.Mor. 855C)5. Esta elección del evento historiable es legítima por parte de Plutarco pero tiene evidentes implicaciones sobre la técnica narrativa. Así pues, la Vida de Alejandro será una narración con una potente enárgeia como corresponde a los objetivos del género literario al que pertenece. Al margen de todo esto, considero que el autor conoce bien la obra de Plutarco y maneja con criterio la bibliografía.

Como conclusión general, al libro quizás le falte analizar cómo afectaron todas estas técnicas narrati-

\section{archai蒡}

n ${ }^{\circ}$ 18, sept.-dec. 2016

César Sierra, Reseña: 'Grethlein, J. (2013). Experience and Teleology in Ancient Historiography. 'Futures Past' from Herodotus to Augustine, Cambridge, Cambridge University Press', p. 407-416 


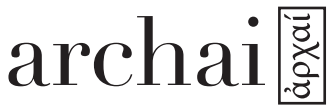

no 18 , sept.-dec. 2016

César Sierra, Reseña: 'Grethlein, J. (2013). Experience and Teleology in Ancient Historiography. 'Futures Past' from Herodotus to Augustine, Cambridge, Cambridge University Press', p. 407-416

414 vas a la ecuanimidad del relato historiográfico. De la misma manera que el autor describe la sensación que se traslada al lector también se puede valorar las intenciones del historiador al construir el relato. Así, la cuidada descripción de un suceso y la minuciosa incorporación de detalles no sólo generan empatía en el lector sino que trasladan una opinión. Dicho de otra manera, el historiador impone su punto de vista con la intención de manipular la memoria colectiva. Por ejemplo, situémonos en el contexto de la guerra del Peloponeso y, concretamente, en los prolegómenos de la campaña en Sicilia. Desde mi punto de vista el objetivo de Tucídides es mostrar lo desacertado de la invasión y lo ignorante que era el dêmos ateniense acerca de la extensión, riqueza y poder de la isla. Para fundamentar esta tesis, Tucídides introduce previamente una digresión etnográfica y geográfica sobre Sicilia, detalla las diferentes posturas de Nicias y Alcibíades en la Asamblea e incluso reflexiona sobre el interés de los jóvenes ateniense en emular las gestas de sus ancestros; utilizando muchas de las técnicas que el autor desarrolla en el libro. Dicho de otro modo, hay una voluntad de generar una opinión y no sólo que el lector experimente una sensación. Por descontado, cuando al historiador no le interesa, todos los detalles y los esfuerzos por recrear la acción histórica desaparecen.

Con todo, considero que Experience and Teleology es un libro muy interesante y que aporta importantes elementos de debate a la historiografía y sus técnicas literarias. Si bien he mostrado algunos puntos de desacuerdo, ello se debe a que el libro genera una profunda reflexión y deja una buena sensación en el lector. Por tanto, un libro totalmente recomendable. 


\section{NoTAS}

1 En un trabajo anterior sugerí que Heródoto realiza un contraste entre el 'mal gobernante' Jerjes/Agameón y el 'buen gobernante' Leónidas/Aquiles y Temístocles/Odiseo; Sierra (2011).

2 Por ejemplo, cito los artículos clásicos de Konishi (1970) y Westlake (1955).

3 Una buena síntesis se encuentra en Mazzarino (1974, p. 253-257).

4 De nuevo un tema muy trabajado, remito a otro clásico; Meier (1987).

5 Un análisis interesante de este escrito desde la historiografía se encuentra en Marincola (1994).

\section{archai圈}

$\mathrm{n}^{\circ} 18$, sept.-dec. 2016

César Sierra, Reseña: 'Grethlein, J. (2013). Experience and Teleology in Ancient Historiography. 'Futures Past' from Herodotus to Augustine, Cambridge, Cambridge University Press', p. 407-416 


\section{archai圈}

$\mathrm{n}^{\mathrm{o}} 18$, sept.-dec. 2016

César Sierra, Reseña: 'Grethlein, J. (2013). Experience and Teleology in Ancient Historiography. 'Futures Past' from Herodotus to Augustine, Cambridge, Cambridge University Press', p. 407-416

\section{BibLIOGRAFÍA}

KONISHI, H. (1970). Thucydides' Method in the Episodes of Pausanias and Themistocles. AJPh $91 \mathrm{n} .{ }^{\circ}$, p.52-69.

MARINCOLA, J. (1994). Plutarch's Refutation of Herodotus. Classical World 25, p.191-203.

MAZZARINO, S. (1974). Il pensiero storico classico. v.1, Roma-Bari, Laterza.

MEIER, Ch. (1987). Historical answers to historical questions: the origins of history in ancient Greece. Arethusa 20 n. ${ }^{\circ} 1-2$, p.41-57.

SIERRA, C. (2011). Jerjes, Leónidas y Temístocles: modelos griegos en el relato de Heródoto. Historiae 8, p.65-91.

WESTLAKE, H. D. (1955). Thucydides and the Pentekontaetia. CQ 5 n. ${ }^{\circ} 1$, p.53-67.

Entregado en Noviembre aceptado para publicación en Diciembre, 2015 